DOI: https://doi.org/10.47405/mjssh.v6i2.645

\begin{tabular}{|c|c|}
\hline+2 & Malaysian Journal of Social Sciences and Humanities (MJSSH) \\
\hline Malaysian Journal of & Volume 6, Issue 2, February 2021 \\
\hline (MJ-ssH) & e-ISSN : 2504-8562 \\
\hline & $\begin{array}{l}\text { Journal home page: } \\
\text { www.msocialsciences.com }\end{array}$ \\
\hline
\end{tabular}

\title{
Impak Perintah Kawalan Pergerakan terhadap Golongan Miskin: Satu Analisis Cerpen "Kuncitara"
}

\author{
Mohamed Nazreen Shahul Hamid1, Rohaya Md Ali', Muhammad Wafi Ramli² \\ 1Pusat Pengajian Bahasa, Tamadun dan Falsafah, Universiti Utara Malaysia (UUM) \\ ${ }^{2}$ Pusat Pengajian Ilmu Kemanusiaan, Universiti Sains Malaysia (USM)
}

Correspondence: Mohamed Nazreen Shahul Hamid (nazreen@uum.edu.my)

\begin{abstract}
Abstrak
Tahun 2020 yang di canang-canangkan sebagai kemuncak ketamadunan moden manusia, akhirnya telah bertukar menjadi mimpi ngeri bagi masyarakat dunia. Hal akibat daripada musuh kecil dan licik, iaitu COVID-19 yang telah meragut jutaan nyawa dan menjadi ancaman global yang digeruni. COVID19 juga menular di Malaysia dengan pengesanan awal pada Januari 2020. Bilangan jangkitan kemudian mencanak naik pada bulan-bulan berikutnya. Bagi memutuskan rantaian jangkitan, pihak kerajaan Malaysia telah melaksanakan Perintah Kawalan Pergerakan (PKP). Namun, langkah ini tidak seindah yang dijangkakan kerana ia memberikan impak yang besar terhadap masyarakat terutamanya golongan miskin. Sebenarnya, situasi pandemik dan PKP yang berlaku ini mendapat perhatian penulis-penulis kreatif yang menzahirkan penceritaan ke dalam bentuk karya kesusasteraan. Oleh itu, dengan mengambil kira cerpen yang dihasilkan oleh Saiful Ghazali yang bertajuk "Kuncitara" (2020), makalah ini bertujuan mengkaji impak PKP terhadap golongan miskin berdasarkan cerpen tersebut. Cerpen ini dianalisis secara tekstual dengan berpandukan konsep sosiologi sastera. Hasil kajian mendapati bahawa, seperti mana yang ditonjolkan dalam cerpen "Kuncitara" terdapat enam tema isu permasalahan yang membelenggu golongan miskin ketika PKP, iaitu ketidakstabilan emosi, tekanan hidup, keganasan tingkah laku, masalah sosial, ancaman kesihatan dan pengingkaran norma. Kajian ini dirujuk signifikan bagi memahami isu-isu yang berlaku terhadap golongan miskin semasa PKP dan membuktikan karya kesusasteraan mampu menjadi saluran yang baik dalam memberi kefahaman kepada masyarakat berkaitan isu-isu tersebut.
\end{abstract}

Kata kunci: Cerpen, golongan miskin, pandemik COVID-19, perintah kawalan pergerakan

\section{The Impact of Movement Control Order on the Poor: An Analysis of the Short Story "Kuncitara"}

\begin{abstract}
The year 2020 touted as the culmination of modern human civilization, has ironically turned into a nightmare for citizen around the world. It is a result of a small and cunning enemy, named COVID-19 which has seized millions of lives and become a dreaded global threat. COVID-19 is also spreading in Malaysia which was first detected in January 2020. The number of infected cases have then increased in the following months. As a measure to break the chain of infection, the Malaysian government has implemented the Movement Control Order (MCO). However, this strategy is not as wonderful as expected because the aftermath of MCO has a huge impact on society, especially the poor. In fact, the pandemic and MCO situation that occurred has attracted the attention of creative writers in expressing
\end{abstract}


storytelling into the form of literary works. Therefore, taking into account the short story produced by Saiful Ghazali entitled "Kuncitara" (2020), this paper aims to identify the impact of MCO on the poor based on the short story. The short story is analyzed textually based on the concept of sociological literature. Finding indicates that, as highlighted in the short story "Kuncitara" there are six themes that plagued the poor during MCO, namely emotional instability, life stress, behavioral violence, social problem, health threat and breach of norm. This study is referred to as significant in order to understand the issues that occur among the poor as well as proving that literary works can be a good channel in giving an insight towards understanding the society regarding those issues.

Keywords: Short story, the poor, COVID-19 pandemic, movement control order

\section{Pengenalan}

2020, tahun yang dijangkakan masyarakat dunia dapat melihat kereta terbang atau negara tercinta Malaysia mencapai status negara maju, sama sekali meleset. Impian mahu pun angan-angan tersebut tampaknya seperti jauh lagi hendak menjadi realiti. Hal ini demikian kerana, dunia pada tahun 2020 terpaksa bertarung dengan musuh licik yang tidak mampu dilihat dengan mata kasar, iaitu koronavirus (coronavirus) ataupun dikenali sebagai COVID-19. COVID-19 telah mengubah landskap dunia berada dalam suasana pandemik yang hingga kini masih belum menemukan titik noktahnya. COVID-19 awalnya dikesan di Bandaraya Wuhan, Hubei, China pada bulan Disember 2019 dan kemudiannya diiktiraf sebagai pandemik secara rasminya pada 11 Mac 2020 oleh Pertubuhan Kesihatan Sedunia (WHO) (World Health Organization, 2020). Sehingga 16 Januari 2021, catatan kes jangkitan COVID19 adalah sebanyak 92,262,621 dengan angka kematian sebanyak 1,995,037 (World Health Organization, 2021) dan diramalkan bahawa angka kematian COVID-19 akan melebihi angka kematian semasa Perang Dunia Pertama dan Perang Dunia Kedua (Sinar Harian, 2020). Keadaan ini menimbulkan kerisauan dalam kalangan ramai pihak terutamanya pihak pemerintah untuk melakukan strategi terbaik bagi membendung pandemik ini.

Di Malaysia, kes pertama COVID-19 adalah dikesan pada akhir Januari 2020, iaitu melibatkan seorang pelancong dari China yang tiba di Johor melalui pintu Singapura (Sipalan, 2020). Pada bulan-bulan seterusnya, angka jangkitan COVID-19 meningkat dengan berleluasa di kebanyakan negeri. Bimbang dengan keadaan tersebut, pada 18 Mac 2020 kerajaan Malaysia di bawah pimpinan Perdana Menteri Muhyiddin Yassin telah melaksanakan Perintah Kawalan Pergerakan (PKP) yang pertama di seluruh negara bagi memutuskan rantaian penyebaran COVID-19 (Sukumaran, 2020). Melalui PKP ini, secara asasnya masyarakat tidak dibenarkan untuk merentas negeri, segala kegiatan ekonomi bukan keutamaan ditangguhkan, aktiviti sosial dilarang untuk dilakukan dan semua institusi pendidikan ditutup serta semua ini adalah tertakluk kepada garis panduan lain yang dikeluarkan oleh Majlis Keselamatan Negara (MKN) dari semasa ke semasa. Menurut Dawood et al. (2020), ketika PKP dilaksanakan oleh kerajaan, masyarakat perlu patuh dengan perintah tersebut yang mana mereka harus tinggal di rumah dan tidak dibenarkan keluar dari kawasan rumah jika tiada urusan penting.

Secara umumnya, PKP yang dilaksanakan ini berjaya membendung penyebaran COVID-19 dalam kalangan rakyat tempatan. Namun, tidak dinafikan juga bahawa PKP turut mendatangkan impak tertentu terutamanya terhadap masyarakat yang berstatus golongan miskin atau B40 yang terpaksa bergelut dengan pelbagai masalah (Hamid et al., 2020). Selain terkesan teruk dari aspek ekonomi lantaran hilang pekerjaan dan sebagainya, golongan miskin atau B40 turut memikul impak besar dari aspek, sosial, kesihatan dan sebagainya (Fischer et al., 2020). Situasi ini dilihat begitu membimbangkan kerana jika ia tidak dapat ditangani dengan baik, boleh membawa kepada pengakhiran yang tidak diingini. Misalnya, semasa PKP terdapat 266 laporan kes bunuh diri yang telah dilaporkan dan 90\% daripadanya adalah melibatkan golongan miskin atau B40 (Miscon, 2020).

Sebenarnya, situasi pandemik dan PKP telah pun mendapat perhatian penulis-penulis kreatif dalam menghasilkan karya-karya mereka. Sebagai perakam zaman dan memiliki daya sensitiviti yang tinggi, penulis-penulis kreatif menghasilkan penceritaan tentang peristiwa yang berlaku ketika pandemik ke 
dalam bentuk karya kesusasteraan seperti cerpen, syair, puisi dan sebagainya. Misalnya, sebuah puisi yang dihasilkan oleh Teo Wei Sing berjudul "Kepada Wira dan Wirawati Negara", yang menceritakan tentang penat lelah dan jasa budi petugas barisan hadapan dalam bertarung nyawa untuk membantu serta menjaga keselamatan nusa dan bangsa di samping menzahirkan puisi tersebut sebagai tanda penghargaan atas pengorbanan mereka sepanjang pandemik (The Malaya Post, 2020; Azizi, 2020). Selain itu, penghasilan buku cerita yang berjudul Engkaulah Adiwiraku oleh Agency Standing Committee Reference Group on Mental Health and Psychosocial Support in Emergency Settings (IASC MHPSS RG) yang diterjemahkan oleh Dr. Feisul Idzwan Mustapha dari Kementerian Kesihatan Malaysia (Inter-Agency Standing Committee, 2020), yang menceritakan tentang realiti sebenar dihadapi oleh golongan kanak-kanak ketika berhadapan dengan situasi pandemik COVID-19 yang memperlihatkan persekitaran seperti ibu bapa, rakan dan peraturan berperanan penting dalam membantu memberi sokongan kepada kanak-kanak untuk menghadapi perubahan hidup disebabkan oleh COVID-19 (Junaidi et al., 2020).

Lanjutan daripada itu, untuk memahami dan mendalami lagi situasi sebenar kehidupan manusia ketika pandemik, sebuah karya lain, iaitu cerpen yang dihasilkan oleh Saiful Ghazali (2020) berjudul "Kuncitara" menceritakan tentang masalah-masalah yang berlaku dalam kalangan golongan miskin ketika PKP yang mana memfokuskan kepada mereka yang tinggal di perumahan kos rendah, iaitu rumah pangsa. Cerpen ini secara halus dan tersirat mengajak pembaca dalam memahami keadaan yang terpaksa dilalui golongan B40 semasa PKP. Bertitik tolak daripada hal ini, cerpen ini dirujuk penting untuk dikaji agar realiti yang mungkin tidak diketahui ramai dapat didedahkan. Malah, kajian ini juga dirujuk signifikan bagi membuktikan karya sastera atau kreatif masih mempunyai peranannya yang tersendiri sewaktu pandemik.

\section{Konsep Sosiologi Sastera}

Secara umumnya, sosiologi dan sastera mempunyai hubungan yang sangat rapat. Hal ini berlaku kerana karya-karya kesusasteraan amat berkait dengan fenomena yang berlaku dalam kehidupan manusia. Malah, kesusasteraan itu sering "menggambarkan hidup" dan "hidup" itu adalah satu realiti sosial (Wellek, 1988). Sehubungan dengan itu, mempelajari sosiologi dalam karya-karya sastera adalah berguna untuk memahami situasi sosial, politik, ekonomi, agama, pandangan dunia dan kreativiti penulis serta lain-lain lagi. Menurut Davita (2005), "Sociology is the study of various traits of society and the relationship between societies to the social stability of their environment". Sosiologi sentiasa mementingkan aktiviti manusia dengan persekitaran mereka. Pengkajian sosiologi juga bukan sahaja meneliti tingkah laku manusia tetapi turut melibatkan elemen seperti struktur masyarakat, kestabilan sosial dan perubahan sosial. Ringkasnya, sosiologi adalah kajian tentang masyarakat dan segala masalah yang wujud dalam institusi sosial, ekonomi, politik, agama dan lain-lain yang terangkum sebagai struktur sosial (Amat, 2011).

Sehubungan dengan itu, sosiologi sastera umumnya bertujuan menjelaskan segala perihal yang berkaitan dengan masyarakat dalam karya-karya kesusasteraan yang terdiri daripada pelbagai genre. Hal ini demikian kerana karya kesusasteraan bukan sekadar bahan bacaan tetapi lebih daripada itu. Dalam hal ini, Sasterawan Negara Shahnon Ahmad menegaskan bahawa sastera adalah seismograf kehidupan yang bermaksud karya kesusasteraan bukan sahaja mencatat tetapi menganalisis hal-hal berkaitan manusia dan masyarakat (Ahmad, 1991). Menerusi karya kesusasteraan, terdapat banyak perkara yang dapati dipelajari dan digali. Oleh yang demikian, dalam kajian sosiologi sastera, karya kesusasteraan itu sering dikatakan sebagai cerminan masyarakat dan terjemahan realiti masyarakat (Tahir, 2006). Dalam erti kata lain, melalui kajian sosiologi sastera, data-data berkaitan masyarakat yang terkandung dalam karya-karya kesusasteraan dapat ditarik keluar untuk dianalisis secara saintifik dan juga objektif. Perbincangan dalam sosiologi sastera adalah melibatkan konteks luar daripada teks atau karya kesusasteraan dan tidak tertumpu pada struktural dalaman teks sahaja.

Melalui sosiologi sastera, salah satu pendekatan paling biasa digunakan hingga ke hari ini untuk mengkaji hubungan kesusasteraan dengan masyarakat adalah dengan menganalisis karya-karya kesusasteraan sebagai dokumen sosial dan juga gambaran tentang realiti sosial (Wellek, 1988). 
Sebenarnya, pendekatan ini merupakan salah satu kegunaan karya-karya kesusasteraan yang paling awal dipegang oleh pengkaji-pengkaji sistematis. Thomas Warton, ahli sejarah puisi Inggeris yang pertama pernah menegaskan bahawa sastera mempunyai keistimewaan merakamkan dengan setia ciriciri zaman dan memelihara penggambaran yang menarik dan paling ekspresif tentang tingkah laku manusia (Wellek, 1988). Malah, menurut beliau lagi karya kesusasteraan adalah kental dengan adat resam, sejarah, politik, ekonomi dan sebagainya. Oleh itu, cerpen "Kuncitara" karya Saiful Ghazali (2020) akan diteliti sebagai dokumen sosial agar analisis tekstual dapat dilakukan secara mendalam dengan mengkategorikan tema-tema isu tertentu yang dihadapi oleh golongan miskin ketika PKP. Dalam pemahaman yang lain, data-data berkaitan yang terkandung dalam cerpen "Kuncitara" akan ditarik keluar agar perbincangan dapat dilakukan. Kajian ini adalah penting bagi memperlihatkan peranan penulis dan karya kesusasteraan itu sendiri ketika pandemik melanda negara serta membuktikan bahawa karya kesusasteraan sentiasa relevan dalam memaparkan sejarah semasa.

\section{Metod Kajian}

Melalui penelitian yang dilakukan, didapati bahawa COVID-19 menjadi perhatian daripada masyarakat keseluruhan melalui penzahiran dalam pelbagai bentuk. Antara bentuk penzahiran tersebut adalah dengan penghasilan karya kesusasteraan sama ada dalam genre prosa atau puisi, cerpen, syair dan sebagainya. Umum sedia maklum bahawa, karya-karya kesusasteraan ini bukan dihasilkan dari ruang yang kosong, sebaliknya adalah daripada pemerhatian penulis-penulis yang menjadi perakam waktu atas segala peristiwa yang berlaku dalam lingkungan masyarakatnya. Oleh itu, tidak mustahil bila berlaku sesuatu peristiwa tertentu sama ada peperangan, pandemik atau bencana alam akan lahir karyakarya hebat di seluruh dunia merakam peristiwa tersebut atau menzahirkan semula peristiwa yang berlaku sebagai renungan di masa hadapan. Misalnya, novel Salina oleh Sasterawan Negara A. Samad Said (1987) yang memaparkan peristiwa dan kehidupan manusia selepas Perang Dunia Kedua sekitar tahun 1950-an. Bersesuaian dengan pemahaman tersebut, kajian ini menggunakan kaedah analisis tekstual berdasarkan konsep sosiologi sastera sebagai metodologi kajian.

\section{Hasil Kajian dan Perbincangan}

Cerpen "Kuncitara" hasil nukilan Saiful Ghazali (2020), memaparkan kisah tentang kehidupan keluarga miskin yang menjalani kehidupan di persekitaran perumahan kos rendah atau dikenali sebagai rumah pangsa ketika pelaksanaan PKP. Terdapat empat watak utama yang memainkan peranan penting dalam cerpen ini, iaitu "Aku”, Emak, Jannah dan Marwan. Jannah dan Marwan merupakan adik kepada "Aku". Jannah dicirikan sebagai seorang yang pemalas dan Marwan pula dikatakan sebagai seorang yang buas dan nakal. Manakala, emak pula digambarkan sebagai seorang yang rajin bekerja dan penyayang. Dari permulaan dan pengakhiran cerpen ini, pembaca dibawa menelusuri kehidupan keluarga miskin ini yang tinggal di kawasan rumah pangsa dan bagaimana PKP memberikan impak kepada mereka sekeluarga.

Berdasarkan analisis tekstual yang dilakukan menerusi cerpen "Kuncitara", didapati bahawa terdapat enam tema masalah yang berlaku terhadap golongan miskin yang tinggal di rumah pangsa ketika PKP. Antaranya adalah (i) ketidakstabilan emosi, (ii) tekanan hidup, (iii) keganasan tingkah laku, (iv) masalah sosial, (v) ancaman kesihatan dan (vi) pengingkaran norma (Lihat Jadual 1).

Menerusi cerpen "Kuncitara", ketidakstabilan emosi dirujuk ketika "Aku" tidak mampu menyesuaikan dirinya dengan keadaan PKP. Dia berasa menyampah dan meluat berkurung di rumah pangsa yang sempit. Dia menganggap PKP merupakan satu azab dalam hidupnya kerana terperangkap di rumah pangsa yang dirujuk sebagai tempat yang sesak. Hal ini disokong oleh Yahaya dan Nor (1993) yang menyatakan bahawa persekitaran rumah pangsa lazimnya dikaitkan dengan keadaan sesak dan kurang kondusif serta akan mewujudkan implikasi negatif terhadap perkembangan dan kesejahteraan diri (Selamat et al., 2018). Hashim (2020) dan Ibrahim (2020) juga menyatakan bahawa tinggal di rumah pangsa ketika PKP akan menyebabkan berlakunya gangguan mental dan tekanan kerana terpaksa bersesak-sesak di kediaman yang sempit. 
Jadual 1: Masalah golongan miskin ketika PKP berdasarkan cerpen Kuncitara

\begin{tabular}{|c|c|}
\hline Tema & Pernyataan \\
\hline \multirow[t]{2}{*}{$\begin{array}{l}\text { Ketidakstabilan } \\
\text { emosi }\end{array}$} & $\begin{array}{l}\text { Perenggan pertama: "aku menyampah, aku meluat. Berapa lama lagi } \\
\text { perlu aku tempuhi azab dari pemerintah ini?"” }\end{array}$ \\
\hline & $\begin{array}{l}\text { Perenggan kelapan: "aku dalam dilema. Hendak keluar bebas atau } \\
\text { terperangkap di dalam flat yang menyesakkan ini?" }\end{array}$ \\
\hline \multirow[t]{3}{*}{$\begin{array}{l}\text { Tekanan } \\
\text { Hidup }\end{array}$} & $\begin{array}{l}\text { Perenggan pertama: "panas. Sempit lagi merimaskan. Bagaikan } \\
\text { haiwan dalam zoo yang terperosok di dalamnya." }\end{array}$ \\
\hline & $\begin{array}{l}\text { Perenggan kedua: "terkinja-kinja dalam rumah flat yang sempit ini. } \\
\text { Menyeksakan dan merimaskan." }\end{array}$ \\
\hline & $\begin{array}{l}\text { Perenggan keempat: "sudah tidak tahan. Duduk di dalam rumah ibarat } \\
\text { sangkar ini amat merimaskan. Sesak. Bising dan busuk. Jiran tetanga } \\
\text { sudah tidak segan-silu. Memaki hamun anak-beranak dengan pekikan } \\
\text { yang bingit. Kata-kata kesat menjadi amalan zikir harian. Hari-hari } \\
\text { mencarut di mulut." }\end{array}$ \\
\hline
\end{tabular}

Keganasan tingkah laku

Masalah sosial

Ancaman kesihatan

Pengingkaran norma
Perenggan kedua: "mahu sahaja aku terajang belakang adik bongsuku itu kuat-kuat. Biar mukanya tersembam atas lantai. Biar giginya terpokah tiga atau empat batang. "

Perenggan kesepuluh: "aku tidak membuang masa. Aku hanya mengambil beberapa langkah lalu aku terajang belakang marwan sekuat hati. Marwan terjatuh dan mukanya tersembam di atas lantai. Giginya aku lihat patah tiga batang. Darah dari gusi marwan bercucuran keluar dari mulutnya."

Perenggan ketiga: "kerjanya menatal telefon dari celik mata sehingga pejam. Langsung tidak berguna. Teman lelaki dua-tiga orang. Aku pun sudah tidak kenal dengan siapa dia berkawan. Asyik bertukar tangan seperti bulu tangkis badminton. Jenis tidak setia."

Perenggan kelima: "penyakit akibat kawasan pembuangan sampah yang dipenuhi tikus dengan bahan buangan yang busuk lagi membusung ulat-temulatnya."

Perenggan kedua belas: "sepanjang jalan yang aku lalui tidak terlalu banyak kenderaan. Laluan lengang. Perintah kawalan pergerakan dipatuhi rakyat. Tetapi aku mematuhi perintah emak. Emak telah memerintahkan aku keluar rumah."

Perenggan ketiga belas: "tidak lama kemudian aku sampai di bengkel yang rakanku maksudkan. Mereka berkumpul beramai-ramai. Rupanya bengkel itu menjadi tempat lepak baharu sementara menunggu perintah kawalan pergerakan tamat." 
Lanjutan daripada itu, tekanan hidup digambarkan oleh "Aku" dengan keadaan tinggal di rumah pangsa yang sempit dan diibaratkan seperti kehidupan haiwan dalam zoo. Perasaan rimas dan seksa dengan keadaan tersebut dizahirkan oleh "Aku" disebabkan oleh perangai adik beradiknya yang bising di samping karenah jiran tetangganya yang suka memaki hamun dan mencarut ahli keluarga mereka sehingga kedengaran oleh penghuni-penghuni rumah yang lain. Keadaan ini secara tidak langsung mewujudkan tekanan hidup dalam diri "Aku". Hal ini juga turut dinyatakan oleh Yusof (2019) dan Yahaya dan Nor (1993), iaitu persekitaran rumah pangsa yang sesak dan bising akan mengundang tekanan dan mengganggu ketenteraman dalam kalangan penghuninya.

Selain itu, keganasan tingkah laku dapat dilihat antara "Aku" dan adiknya, Marwan. Marwan ialah seorang adik bongsu yang buas dan nakal serta disifatkan oleh "Aku" seperti seekor mawas. "Aku" mempunyai perasaan tidak puas hati terhadap Marwan disebabkan oleh kenakalannya. Disebabkan itu, tercetus niat dalam diri "Aku" untuk bertindak ganas terhadap Marwan seperti ingin terajang dengan kuat sehingga muka dan gigi Marwan cedera. Akhirnya, niat dan impian "Aku" untuk mencederakan Marwan menjadi kenyataan apabila dia mula bertindak ganas dengan melakukan terajang sehingga wajah dan gigi Marwan cedera. Tindakan ini terjadi kerana Marwan bermain bola dalam rumah sehingga mengakibatkan televisyen pecah akibat tendangan bola tersebut. Hal ini selari dengan kenyataan oleh Anwar (2020), iaitu golongan miskin akan jauh lebih terkesan dengan pandemik (merujuk kepada PKP) yang mana kemungkinan besar hidup mereka diancam keganasan atau cenderung kepada keganasan (Buheji et al., 2020).

Tambahan pula, masalah sosial dapat dilihat pada adik "Aku", iaitu Jannah yang dirujuk sebagai seorang yang tidak berguna oleh "Aku" kerana mempunyai sikap malas dan selalu bermain dengan telefon bimbitnya. Jannah juga merupakan seorang perempuan yang suka bertukar-tukar pasangan hidup. Hal ini menunjukkan bahawa Jannah cenderung untuk bergelumang dengan gejala sosial. Sharif dan Roslan (2011) menegaskan bahawa gejala sosial merupakan fenomena modenisasi dan kejutan budaya yang melanda golongan remaja yang mana mereka berdepan dengan krisis pembentukan dan pengembangan identiti diri serta mereka yang hidup dalam persekitaran miskin mudah untuk terlibat dengan gejala sosial seperti pergaulan bebas (Ramli et al., 2019). Pauzi (2017) juga menyatakan bahawa kawasan kediaman kos rendah seringkali dilabel sebagai kawasan pembiakan tingkah laku negatif dalam kalangan penghuninya yang muda.

Seterusnya, ancaman kesihatan pula dirujuk pada keadaan kawasan rumah pangsa yang menggambarkan suasana dan persekitaran kotor. Persekitaran rumah pangsa lazimnya sangat teruk dari aspek kebersihan sama ada ia berpunca daripada sikap penghuni yang mementingkan diri sendiri ataupun pihak pengurusan yang tidak memainkan peranan dan bertanggungjawab. Hal ini boleh mengundang kepada pelbagai masalah kesihatan dalam kalangan penghuni. Muzafar dan Kunasekaran (2020) menyatakan bahawa persekitaran rumah yang kotor dan sesak lazimnya berkait dengan kadar penyakit yang tinggi. Hal ini juga ditambah lagi dengan kewujudan haiwan perosak seperti tikus dan ulat yang kebiasaannya dilihat mengerumuni kawasan sampah-sarap, selain menyebarkan penyakit berjangkit yang boleh mengancam kesihatan (Satibi, 2019).

Di samping itu, pengingkaran norma dapat dilihat pada keadaan yang mana emak "Aku" menghalaunya keluar dari rumah setelah dia terajang Marwan. Sejak itu, "Aku" mengambil keputusan keluar dari rumah untuk melepak bersama rakan-rakannya walaupun PKP masih dilaksanakan. Sewaktu PKP, semua rakyat perlu berada di rumah masing-masing sebagai langkah untuk membasmi rantaian pandemik. Namun, "Aku" tidak mengendahkan larangan PKP tersebut. Hal ini menunjukkan golongan miskin yang mempunyai masalah di rumah ketika PKP cenderung untuk melakukan tindakan delinkuen yang mana tindakan tersebut merupakan satu pengingkaran norma dan peraturan yang ditetapkan oleh kerajaan seperti tidak berada di rumah ketika PKP. Hal ini selari dengan kenyataan Tunggak et al. (2015) yang menyatakan menegaskan bahawa tindakan delinkuen wujud disebabkan oleh kemiskinan yang dialami oleh sesebuah keluarga. 


\section{Kesimpulan}

Kesimpulannya, kajian ini berjaya membongkar masalah berbangkit dalam kalangan golongan miskin yang tinggal di kawasan rumah pangsa ketika PKP menerusi cerpen "Kuncitara". Pelaksanaan PKP ternyata memberi impak yang signifikan terhadap golongan miskin dari pelbagai aspek yang semestinya melibatkan emosi, tingkah laku dan persekitaran mereka. Cerpen ini berjaya membawa para pembaca mendalami sisi kehidupan golongan miskin yang tinggal di rumah pangsa ketika PKP. Kajian ini berhasil dalam membedah cerpen "Kuncitara" bagi memberi pemahaman yang jelas kepada masyarakat untuk lebih memahami kehidupan golongan miskin yang bertarung dengan masalahmasalah hidup yang kompleks ketika PKP. Selain itu, kajian ini juga berjaya membuktikan bahawa karya kesusasteraan yang dihasilkan semasa pandemik mempunyai tujuan memberi kesedaran kepada masyarakat berhubung perkara berkaitan menjaga kesihatan, mengikut peraturan yang betul ketika bencana, kasih mengasihi semasa masyarakat dan sebagainya.

\section{Rujukan}

Ahmad, S. (1991). Sastera sebagai seismograf kehidupan. Kuala Lumpur: Dewan Bahasa dan Pustaka.

Amat, A. (2011). Ngayau sebagai sebuah novel berwarna tempatan: Satu kajian sastera. MANU-Jurnal Pusat Penataran Ilmu dan Bahasa, 17, 39-56.

Anwar, N.I. (2020, 17 Mei). Kemiskinan multidimensi dalam era Covid-19. Sinar Harian. Dicapai daripada https://www.sinarharian.com.my/article/83964/KHAS/Pendapat/Kemiskinanmultidimensi-dalam-era-Covid-19

Azizi, M.A.Q. (2020, 22 Mac). Puisi buat wira, wirawati negara 'berperang' hadapi Covid-19, ilham selepas rakan dijangkiti - "Tapi masih ada yang degil, ingkar perintah". mStar. Dicapai daripada https://www.mstar.com.my/xpose/figura/2020/03/22/puisi-kepada-wira-wirawati-negara

Buheji, M., Cunha, K.D.C., Beka, G., Mavric, B., de Souza, Y.L.D.C, Silva, S.S.D.C, Hanafi, M., \& Yein, T.C. (2020). The extent of covid-19 pandemic socio-economic impact on global poverty. A global integrative multidisciplinary review. American Journal of Economics, 10(4), 213-224.

Davita, R. (2005). Human and literature. London: Styles.

Dawood, S.R.S., Ramli, M.W., \& Som, S.H.M. (2020). Daya tahan warga emas dalam era pandemik: Satu tinjauan awal sewaktu perintah kawalan pergerakan (PKP) di Pulau Pinang, Malaysia. GEOGRAFI, 8(2), 110-128.

Fischer, F., Raiber, L., Boscher, C., \& Winter, M.H.J. (2020). COVID-19 and the elderly: Who cares?. Frontiers in Public Health, 8(151), 1-3.

Hamid, M.N.S., Ali, R.M., \& Ramli, M.W. (2020). Pandemik dalam karya sastera: Ceritera kehidupan manusia. In Hassan, A.F.M, Alimi, K.F., Mutalib, M.A., Yahya, M.A., \& Ibrahim, M.Z.T (Eds.), e-Prosiding NARADATA 2020: Penyelidikan Bahasa, Sastera dan Budaya dalam Era Pandemik (pp. 191-201). Pusat Pengajian Bahasa, Tamadun dan Falsafah: Universiti Utara Malaysia.

Hashim, R. (2020, 30 April). PKP jangan sampai celaru mental. Sinar Harian. Dicapai daripada https://www.sinarharian.com.my/article/81260/ANALISIS-SEMASA/PKP-jangan-sampai-celarumental

Ibrahim, Z. (2020, 23 Mac). Tidak boleh keluar rumah, keluarga B40 berhimpit sebumbung. The Malaysian Insight. Dicapai daripada https://www.themalaysianinsight.com/bahasa/s/231074

Inter-Agency Standing Committee. (2020). "Engkaulah Adiwiraku". Dicapai daripada https://interagencystandingcommittee.org/system/files/202005/My\%20Hero\%20is\%20You\%2C\%20Storybook\%20for\%20Children\%20on\%20COVID$19 \% 20 \% 28$ Bahasa\%20\%20Malay\%29.pdf

Junaidi, R., Ali, T.I.M.T.M., \& Mamat, M. (2020). Pandemik COVID-19 dalam persekitaran kanakkanak menerusi Engkaulah Adiwiraku. PENDETA: Journal of Malay Language, Education and Literature, 11, 31-45.

Miscon, S.N.Z. (2020, 18 November). 266 kes bunuh diri semasa PKP, faktor tertinggi disebabkan beban hutang. Malaysia Dateline. Dicapai daripada https://malaysiadateline.com/266-kes-bunuhdiri-semasa-pkp-faktor-tertinggi-disebabkan-beban-hutang/ 
Muzafar, P.M.M., \& Kunasekaran, T. (2020). Three major threats - money, food and living conditions. Kuala Lumpur: Khazanah Research Institute.

Pauzi, H.M. (2017). Konsistensi matlamat dan objektif Program Perumahan Kos Rendah dengan keperluan perumahan kumpulan sasar. The Malaysian Journal of Social Administration, 9(1), 87106.

Ramli, M.W., Dawood, S.R.S., \& Som, S.H.M. (2019). Cabaran hidup miskin dalam kalangan komuniti nelayan di Tanjung Dawai, Kedah. Geografia-Malaysia Journal of Society and Space, 15(1), 54-66.

Saiful Ghazali. (2020). "Kuncitara". SelangorKini. Dicapai daripada https://selangorkini.my/2020/04/kuncitara/

Satibi, Z. (2019, 23 Jun). Bela 40 haiwan di rumah. myMetro. Dicapai daripada https://www.hmetro.com.my/ekspresi/2019/06/467987/bela-40-haiwan-di-rumah

Selamat, M.N., Ibrahim, F., Nen, S., Sarnon, N., Subhi, N., Shaari, A.H., Sannusi, S.N., \& Rahman, Z.A. (2018). Keselamatan persekitaran perumahan dalam kalangan remaja di kawasan Program Perumahan Rakyat (PPR). Geografia-Malaysian Journal of Society and Space, 14(4), 115-126.

Sharif, Z., \& Mohamad Roslan, N. (2011). Faktor-faktor yang mempengaruhi remaja terlibat dalam masalah sosial di Sekolah Tunas Bakti, Sungai Lereh, Melaka. Journal of Education Psychology \& Counselling, 1(7), 115-140.

Sinar Harian. (2020, 13 April). Korban Covid-19 diramal melebihi mangsa Perang Dunia. Dicapai daripada https://www.sinarharian.com.my/article/78654/KHAS/Covid-19/Korban-Covid-19diramal-melebihi-mangsa-Perang-Dunia

Sipalan, J. (2020, 25 Januari). Malaysia confirms first cases of coronavirus infection. Reuters. Dicapai daripada https://fr.reuters.com/article/us-china-health-malaysia-idCAKBN1ZO065

Sukumaran, T. (2020, 16 Mac) "Coronavirus: Malaysia in partial lockdown from March 18 to limit outbreak. South China Morning Post. Dicapai daripada https://www.scmp.com/week-asia/healthenvironment/article/3075456/coronavirus-malaysias-prime-minister-muhyiddin-yassin

Tahir, U.M.M. (2006). Pemahaman dan penerapan sosiologi sastera dalam sastera Melayu moden. Akademika-Journal of Southeast Asia Social Sciences and Humanities, 69(1), 3-16.

The Malaya Post. (2020, $21 \mathrm{Mac})$. Sajak untuk wira dan wirawati negara Covid-19 - Cikgu Teo. Dicapai daripada https://www.themalayapost.my/sajak-untuk-wira-dan-wirawati-negara/

Tunggak, B., Ngadi, S., \& Naim, H.A. (2015). Delinkuen pelajar dan cadangan penyelesaiannya menerusi model pembangunan sahsiah remaja/pelajar muslim bersepadu. Jurnal Hadhari, 7(2), 11-30.

Wellek, R. (1988). Theory of Literature. London: Harcourt Brace Jovanovich.

World Health Organization. (2020, $11 \mathrm{Mac}$ ). WHO Director-General`s Opening remarks at the media briefing on COVID-19. Dicapai daripada https://www.who.int/dg/speeches/detail/who-directorgeneral-s-opening-remarks-at-the-media-briefing-on-covid-19---11-march-2020

World Health Organization (2021). WHO Coronavirus Disease (COVID-19) Dashboard. Dicapai daripada https://covid19. who.int/

Yahaya, N., \& Norlela, M.N. (1993). Kesejahteraan remaja di rumah pangsa: Tumpuan kepada penggunaan ruang untuk belajar dan aktiviti sosial. Pendidik dan Pendidikan, 12, 92-102.

Yusof, N. (2019). Faktor penyumbang kepada tekanan perumahan di kawasan perumahan kos rendah dan sederhana rendah di Pulau Pinang. KEMANUSIAAN: The Asian Journal of Humanities, 26(1), 143-171. 